\title{
Silicon/Biogas-Derived Carbon Nanofibers Composites for Anodes of Lithium-Ion Batteries
}

\author{
Ignacio Cameán ${ }^{1, *}$, Nuria Cuesta ${ }^{1}$, Alberto Ramos ${ }^{2}$ (D) and Ana B. García ${ }^{1}$ (i) \\ 1 Instituto de Ciencia y Tecnología del Carbono, INCAR-CSIC, Francisco Pintado Fe 26, 33011 Oviedo, Spain; \\ n.cuesta@incar.csic.es (N.C.); anabgs@incar.csic.es (A.B.G.) \\ 2 Universidad de Castilla-La Mancha, 13071 Ciudad Real, Spain; alberto.ramos@uclm.es \\ * Correspondence: icamean@incar.csic.es; Tel.: +34-9-8511-9090
}

Received: 17 March 2020; Accepted: 22 April 2020; Published: 24 April 2020

check for updates

\begin{abstract}
The electrochemical performance of novel nano-silicon/biogas-derived carbon nanofibers composites (nSi/BCNFs) as anodes in lithium-ion batteries was investigated, focusing on composition and galvanostatic cycling conditions. The optimization of these variables contributes to reduce the stress associated with silicon lithiation/delithiation by accommodating/controlling the volume changes, thus preventing anode degradation and therefore improving its performance regarding capacity and stability. Specific capacities up to $520 \mathrm{mAh} \mathrm{g}^{-1}$ with coulombic efficiency $>95 \%$ and $94 \%$ of capacity retention are achieved for $\mathrm{nSi} / \mathrm{BCNFs}$ anodes at electric current density of 100/200 $\mathrm{mA} \mathrm{g}^{-1}$ and low cutoff voltage of $80 \mathrm{mV}$. Among the BCNFs, those no-graphitized with fishbone microstructure, which have a great number of active sites to interact with nSi particles, are the best carbon matrices. Specifically, a nSi:BCNFs 1:1 weight ratio in the composite is the optimal, since it allows a compromise between a suitable specific capacity, which is higher than that of graphitic materials currently commercialized for LIBs, and an acceptable capacity retention along cycling. Low cutoff voltage in the $80-100 \mathrm{mV}$ range is the most suitable for the cycling of $\mathrm{nSi} / \mathrm{BCNFs}$ anodes because it avoids formation of the highest lithiated phase $\left(\mathrm{Li}_{15} \mathrm{Si}_{4}\right)$ and therefore the complete silicon lithiation, which leads to electrode damage.
\end{abstract}

Keywords: silicon; biogas-derived carbon nanofibers; anodes; lithium-ion batteries

\section{Introduction}

In the last decades, the market of lithium-ion batteries (LIBs) has increased enormously due to, mainly, the vertiginous growth of the portable electronic devices (mobile phones, tablets, laptop computers, etc.) that use them. Furthermore, these batteries are also an attractive and feasible alternative for the development of massive electric energy storage systems to allow the implementation of renewable energy sources, as well as the electric vehicle, thus contributing to the transition from an energy model based on fossil fuels to other more sustainable. Consequently, intensive research is being carried out to improve the overall performance of LIBs by increasing both the energy density and power and extending the lifetime, which are all largely governed by the electrode materials. In this respect, the development of new electrode materials to replace graphite and $\mathrm{LiCoO}_{2}$, traditionally used in anodes and cathodes of LIBs, respectively, is receiving worldwide attention by researchers [1,2]. Respecting anode materials, silicon has emerged as a promising alternative due to the high theoretical specific capacity (the richest $\mathrm{Li}_{x} \mathrm{Si}$ phase at room temperature is $\mathrm{Li}_{15} \mathrm{Si}_{4}$, which corresponds to $3579 \mathrm{mAh} \mathrm{g}^{-1}$ ), the relatively low working potential (delithiation voltage of $\mathrm{Si}$ is $\sim 0.4 \mathrm{~V} \mathrm{vs.} \mathrm{Li}^{\prime} / \mathrm{Li}^{+}$), the abundance in earth crust and the existence of an industrial manufacturing process [3-6]. However, the lithiation of Si causes successive expansions of its internal structure, leading to particles' fracture and consequent loss of electric contact between them, as well as a continuous formation-breaking-formation of the 
solid electrolyte interphase (SEI) layer [7]. In addition, the low electric conductivity of silicon could also cause a large polarization of the electrode [8]. As a result, Si has shown poor cycling stability and reversibility.

To tackle the silicon electrode degradation, several strategies have been developed, among them, the use of nanostructured silicon (nanowires, nanofilms and nanotubes) with higher intrinsic porosity than micrometric silicon, to accommodate the lithiation volume changes, thus reducing the associated stress. Furthermore, the nanometric particle size of the electrode materials has the additional advantage of lowering the diffusion time of the lithium ions for the insertion/deinsertion processes, i.e., faster charge/discharge rate [9]. In this context, there are numerous works in which the performance of nanostructured $\mathrm{Si}$ as anode in LIBs was investigated. As an example, silicon nanowires and surface-modified silicon nanowires showed reversible specific capacities up to 778 and $2348 \mathrm{mAh}$ $\mathrm{g}^{-1}$ after 200 and 15 charge-discharge cycles, respectively [10]. Regardless of the encouraging results, the large-scale application of these nanomaterials is not realistic when considering their complex and, therefore, high-cost production process.

Another promising strategy is to prepare Si-based composites by adding an inactive/active matrix, which can help to accommodate the volume changes, thereby improving the performance of the electrode compared to one of pure Si [11]. In this context, carbon materials such as carbon nanofibers, graphene or reduced graphene oxide, among others, are widely investigated for this application, because they are highly conductive, providing efficient electron transport, lightweight and ductile, and they also form stable SEI layers [12-14]. Silicon/carbon composites are usually synthesized by mechanical milling of active and matrix materials, via pyrolysis of carbon and silicon precursors or a combination of both methods $[15,16]$. Although there are more procedures, such as electrospinning, etching, chemical vapor deposition, etc. $[12,13,16]$, from a practical point of view, mechanical milling and pyrolysis techniques have lower cost and high-throughput syntheses, so they appear the most suitable option for the industrial-scale production of silicon/carbon composites [16].

On the other hand, polyvinylidene fluoride (PVDF), which is traditionally used in graphite anodes, proved not to be an effective binder for Si-based anodes, because it does not have enough elongation capability to resist the volume expansion. The identification of alternative binders to endure the electrode integrity by maintaining the contact between silicon particles is, therefore, another interesting approach. Special mention should be made of water-processed polymeric binders, such as polyacrylic acid [17] and its sodium salt [18], sodium carboxymethyl cellulose with [19-21] or without [22-27] styrenebutadiene rubber, sodium alginate [28], carboxymethyl chitosan [29], guar gum [30] and arabic gum [31].

In summary, there are several variables related to composition and preparation of silicon/carbon-based anodes that exert substantial influence on their electrochemical performance in LIBs. Nevertheless, these variables are, in general, considered in an isolated way [11]. Based on this, herein a preliminary study to optimize the anode electrochemical properties as regards type of silicon (nanometer or micrometer size), preparation methodology of silicon/carbon active composite (simple mixture, ball-milling and dispersion in solvents), and nature and quantity of electrode binder (sodium carboxymethyl cellulose and xanthan gum) was firstly carried out (see Supplementary Materials). Furthermore, biogas-derived carbon nanofibers (BCNFs) were investigated for the first time as potential carbon matrices for Si-based anodes of LIBs. These carbon materials have been previously obtained by catalytic decomposition of biogas, a renewable energy source, to simultaneously produce syngas, which appears an alternative interesting option to the main use in co-generation combustion plants, for the production of heat and electricity. Moreover, $\mathrm{BCNFs}$ can be further heat-treated at high temperatures, to transform them into graphitic nanofibers [32]. From this preliminary study, it was concluded that the most suitable electrodes are those in which the active composite was prepared by dispersing nano-silicon (nSi) and BCNFs in iso-propanol, and using a $20 \mathrm{wt} . \%$ of sodium carboxymethyl cellulose as binder. By this cost-effective, fast, simple and easy scalable procedure, nSi/BCNFs-based anodes 
with a homogeneous distribution of the silicon particles in the carbonaceous matrix, as well as good cycling stability, have been achieved.

Lastly, the least explored strategy deals with the influence of the cycling conditions in the microstructural changes of silicon [33]. For instance, some authors have observed an improvement of capacity retention by increasing the lower cutoff voltage from $3 \mathrm{mV}$ (lower voltage traditionally used to prevent deposition of metallic lithium) to $>50 \mathrm{mV}$ [34-37]. According to Obrovac et al., this effect is due to the formation of a stable microstructure composed of a central crystalline $\mathrm{Si}$ that remains intact and a crust of amorphous $\mathrm{Si}$ in charge of the accommodation of the lithium ions, which could favor the electrode capacity retention since it would allow a greater control of the volume changes [37].

\section{Materials and Methods}

Materials: source, preparation and characterization. Micro-crystalline silicon (mSi) of $99 \mathrm{wt} . \%$ trace metal basis and nano-crystalline silicon (nSi) of $>97 \mathrm{wt} . \%$ purity powders with particle sizes of $44 \mu \mathrm{m}$ and 10-30 nm, respectively, from Sigma-Aldrich and Strem Chemicals were used as electrode materials. Metal-free (BCNF16A and BCNF27 ${ }^{*}$ ) and graphitized $\left(B C N F 27^{*} G\right)$ biogas-derived carbon nanofibers were selected as carbon matrices for the preparation of the $\mathrm{nSi} / \mathrm{BCNFs}$ active composites to be further tested in the electrodes. BCNF16A and $\mathrm{BCNF} 27^{*} \mathrm{~A}$ were prepared by the acidic treatment with $\mathrm{HNO}_{3} / \mathrm{HF}$ of two carbon nanofibers (BCNF16 and BCNF27*) produced in the catalytic decomposition of biogas. BCNF27* $\mathrm{G}$ was obtained by the heat treatment at $2600^{\circ} \mathrm{C}$ of $\mathrm{BCNF} 27^{*}$ in a graphite electric furnace for $1 \mathrm{~h}$, in argon flow. The experimental set up and BCNFs properties can be found in Cuesta et al. [32]. For comparative purposes, two commercial carbon nanomaterials, reduced graphene oxide (rGO) supplied by Graphenea (Donostia, Spain) and carbon nanofibers from Pyrograf (Cedarville, $\mathrm{OH}, \mathrm{USA})$, which were graphitized by heat treatment at $2800^{\circ} \mathrm{C}$ (PR24G) in a previous work [38], were also selected as carbon matrices for $\mathrm{nSi} / \mathrm{C}$ active composites. Carbon black $\mathrm{C} 65$ (CB) and synthetic KS6 graphite (SG-KS6) from Ymeris Graphite \& Carbon (Bironico, Switzerland), as well as the graphitic BCNF27*G nanofilaments, were tested as conductive additives (E) for the Si-based anodes. Finally, the biopolymers sodium carboxymethyl cellulose $(\mathrm{NaCMC})$ supplied by Sigma-Aldrich and Xanthan gum (XG) provided by Industrias ROKO (Llanera, Spain) were used as electrode binders.

The textural properties of the BCNFs were determined by $\mathrm{N}_{2}$ adsorption-desorption at $-196{ }^{\circ} \mathrm{C}$, in a Micromeritics ASAP 2420 volumetric adsorption system. The samples were previously degassed overnight at $250^{\circ} \mathrm{C}$. The Brunauer-Emmett-Teller (BET) method was applied to calculate the specific surface areas $\left(S_{\mathrm{BET}}\right)$ by taking $0.162 \mathrm{~nm}^{2}$ for the cross-sectional area of the $\mathrm{N}_{2}$-adsorbed molecule. The total pore volumes $\left(V_{\mathrm{t}}\right)$ were determined from the amount of gas adsorbed at $p / p_{0}=0.97$. Mesopore $(2-50 \mathrm{~nm})$ and micropore volumes were calculated from the cumulative pore size distributions obtained by applying Density Functional Theory (DFT) methods to the $\mathrm{N}_{2}$ adsorption isotherms $\left(p / p_{0}=0.97\right)$.

$n S i / C$ composites: preparation. The $\mathrm{nSi} / \mathrm{C}$ composites used as active materials in the anodes, which included CB conductive additive (this material was selected from the results of the preliminary study found in the Supplementary Materials), were prepared by following three methodologies, namely, Simple Addition (SA), Mechanical Milling (MM) in a laboratory Mixer Mills MM400 from Retsch during $30 \mathrm{~min}$, and Dispersion in 2-Propanol (DP) by vigorously magnetic stirring at $70{ }^{\circ} \mathrm{C}$ of the components: $\mathrm{nSi}$ (from 10 to $80 \mathrm{wt} . \%$ ), the corresponding $\mathrm{C}$ matrix (from 80 to $10 \mathrm{wt} . \%$ ) and the selected $\mathrm{E}$ additive (10 wt.\%). In the DP, the resultant wet dispersion was then dried overnight at $60{ }^{\circ} \mathrm{C}$, to remove the solvent. The $\mathrm{nSi} / \mathrm{C}$ composites were generically designated as $x \mathrm{nSi} / y \mathrm{C} / z \mathrm{CB}$, in which $x, y$ and $z$ are the weight percentages of $\mathrm{nSi}$, carbon matrix and conductive additive, respectively; i.e., $60 \mathrm{nSi} / 30 \mathrm{BCNF} 16 \mathrm{~A} / 10 \mathrm{CB}$ is a composite with $60 \mathrm{wt} . \%$ of $\mathrm{nSi}, 30 \mathrm{wt} . \%$ of BCNF16A (biogas-derived carbon nanofibers) and $10 \mathrm{wt} . \%$ of $\mathrm{CB}$ (Carbon black C65). However, since the E proportion was fixed to $10 \mathrm{wt} . \%$, this designation can be simplified as $60 \mathrm{nSi} / 30 \mathrm{BCNF} 16 \mathrm{~A} / \mathrm{CB}$, generically $x \mathrm{nSi} / \mathrm{yC} / \mathrm{CB}$.

Electrode preparation, cell assembly and electrochemical measurements. The working electrodes were prepared by mixing, in a laboratory Mixer Mills MM400 from Retsch, $80 \mathrm{wt} . \%$ of the active component ( $\mathrm{mSi}, \mathrm{nSi}$ or $\mathrm{nSi} / \mathrm{C}$ composite, including the $\mathrm{E}$ additive in this percentage) and $20 \mathrm{wt} . \%$ of the binder 
(in an aqueous solution at a concentration of ca. $1 \mathrm{wt} . \%$ ) during $30 \mathrm{~min}$ at $15 \mathrm{~s}^{-1}$. Weight ratios of $\mathrm{mSi}$ or $\mathrm{nSi} / \mathrm{E} /$ Binder of 80:10:10 were also used for some preliminary experiments (see Supplementary Materials). Two to three drops of the resultant slurry were spread onto a $12 \mathrm{~mm}$ diameter and $25 \mu \mathrm{m}$ thickness copper disc, dried at $60{ }^{\circ} \mathrm{C}$ and then hydraulically pressed at a pressure in the range of 9-90 MPa. The loads (active material + binder) in mg of the different working electrodes that were calculated by weight difference are provided in Table S1 of the Supplementary Materials. Following composites designation, the working electrodes were denoted as $(x \mathrm{nSi} / y \mathrm{C} / z \mathrm{E}) 20 \mathrm{~B}$, in which the parenthesis corresponds to $\mathrm{nSi} / \mathrm{C}$ composite $(80 \mathrm{wt} . \%$ in the electrode) and $20 \mathrm{~B}$ concerns to $20 \mathrm{wt} . \%$ of binder, i.e., (60nSi/30BCNF16A/10CB)20NaCMC is an electrode composed by $80 \mathrm{wt} . \%$ of a composite $\mathrm{nSi} / \mathrm{C}$ ( $60 \mathrm{wt} . \%$ of nSi, $30 \mathrm{wt} . \%$ of BCNF16A carbon matrix and $10 \mathrm{wt} . \%$ of CB carbon black) and $20 \mathrm{wt} . \%$ of $\mathrm{NaCMC}$ binder. However, as before, since the proportion of binder in the electrode was constant, this designation can be simplified as $(60 \mathrm{nSi} / 30 \mathrm{BCNF} 16 \mathrm{~A} / \mathrm{CB}) \mathrm{NaCMC}$, generically $(x \mathrm{nSi} / y \mathrm{C} / \mathrm{E}) \mathrm{B}$.

Before cycling, the electrodes were examined by Scanning Electron Microscopy (SEM), using a FEI Quanta FEG 650, which was connected to Energy Dispersive X-ray Spectroscopy (EDX) ametek-EDAX with an Apollo X detector.

Two-electrode (working + counter) Swagelok cells were used for evaluating the performance as anodes of the working electrodes. A metallic lithium disc of $12 \mathrm{~mm}$ of diameter was the counter electrode. The cells were assembled in a dry box with $\mathrm{O}_{2}$ and $\mathrm{H}_{2} \mathrm{O}$ contents below $0.1 \mathrm{ppm}$. The electrodes were separated by two micro-fiber glass discs impregnated with a few drops of the electrolyte solution, $1 \mathrm{M}$ $\mathrm{LiPF}_{6}$ in ethylene carbonate (EC): diethyl carbonate (DEC), 1:1, $w: w$, and $\sim 1-5 \%$ of vinylene carbonate (VC). The initial potential of the cells was in the range $2.90-3.10 \mathrm{~V}$ vs. $\mathrm{Li} / \mathrm{Li}^{+}$.

The electrochemical measurements of the cells were conducted in a Biologic multichannel VMP2/Z potentiostat/galvanostat. Galvanostatic cycling was performed in the potential ranges of $2.1 \mathrm{~V}-3 \mathrm{mV}$ vs. $\mathrm{Li} / \mathrm{Li}^{+}$and $0.9 \mathrm{~V}-\mathrm{X} \mathrm{mV}$ vs. $\mathrm{Li} / \mathrm{Li}^{+}(X=3,20,40,60,80,100$ and $120 \mathrm{mV}$, to determine the optimal lower cutoff voltage), at an electric constant current density of $100 \mathrm{~mA} \mathrm{~g}^{-1}$, for 30 and 50 charge-discharge cycles, respectively. Once the optimal lower cutoff voltage was assessed, additional experiments were carried at a higher electric current density of $200 \mathrm{~mA} \mathrm{~g}^{-1}$.

\section{Results and Discussion}

Based on the results of the preliminary optimization study (see Supplementary Materials), the most suitable electrodes are composed by $80 \mathrm{wt} . \%$ of the $\mathrm{nSi} / \mathrm{C}$ active composite and $20 \mathrm{wt} . \%$ of the NaCMC binder. The composite was prepared by mixing in iso-propanol the nano-silicon, the carbon matrix and $10 \mathrm{wt} . \%$ of $\mathrm{CB}$ conductive additive. Therefore, the working electrodes considered hereinafter are those denoted as $(x \mathrm{nSi} / y \mathrm{BCNFs} / \mathrm{CB}) \mathrm{NaCMC}$, in which the composite is formed by 80-10 wt. $\%$ of BCNF27*G, BCNF27*A, BCNF16A, rGO or PR24G carbon matrices, $10-80 \mathrm{wt} . \%$ of nSi and $10 \mathrm{wt} . \%$ of $\mathrm{CB}$ conductive additive.

\subsection{Influence of $n$ Si Proportion and BCNFs Carbon Matrices on the Electrochemical Performance of $n S i / B C N F s$ Anodes}

The main electrochemical parameters, specific discharge capacity $\left(C_{\text {disc }}\right)$ in the 1 st, 2 nd, 10th, 20th and 30th cycles, irreversible capacity in the 1st discharge-charge cycle $\left(C_{\text {irr }}\right)$ and capacity retention $(R)$ from the galvanostatic cycling of several Si-based anodes with different proportions of $\mathrm{nSi}$ and BCNFs carbon matrices vs. $\mathrm{Li}^{-\mathrm{Li}^{+}}$in $1 \mathrm{M} \mathrm{LiPF}_{6}$ in EC:DEC (1:1, w:w) with 1-5 wt. $\%$ of $\mathrm{VC}$, at an electric current density of $100 \mathrm{~mA} \mathrm{~g}^{-1}$, are summarized in Table 1 and the plots of the specific capacity versus cycle number for some of them appear in Figure 1. To simplify the discussion, they were designated as $x \mathrm{nSi} / y \mathrm{BCNFs}$. For comparison, an electrode containing only $\mathrm{nSi}$ as active material was also tested. From a general perspective of this data, it can be confirmed that the combination of nSi with BCNFs materials may improve substantially the nSi electrode performance as regards both capacity provided and stability. For example, a discharge capacity of $564 \mathrm{mAh} \mathrm{g}^{-1}$ (being always referred to the mass of the active composite material) at the end of cycling (30 discharge-charge cycles) was determined for 
45nSi/45BCNF16A electrode in contrast to a value of only $118 \mathrm{mAh} \mathrm{g}^{-1}$ for nSi electrode; moreover, the discharge capacity retention along cycling of the former is much higher (33\% against $8 \%$ ). However, the scope of this improvement depends largely on nSi:BCNFs' weight ratio. Regardless of carbon matrix, the presence of small relative $\mathrm{nSi}$ amounts $(\leq 30 \mathrm{wt}$. $\%$ in the active composite, $\mathrm{nSi}$ :BCNFs weight percentage ratios of 30:60 or 10:80) is not enough to reach acceptable capacities (at least in the order of those determined for graphite electrodes in LIBs). On the contrary, larger $\mathrm{nSi}$ proportions ( $\geq 60 \mathrm{wt} . \%$ in the active composite, $\mathrm{nSi}: \mathrm{BCNFs} 80: 10$ or 60:30) allow the insertion of a significant number of $\mathrm{Li}^{+}$ions in the first cycles, as shown by the values of the discharge capacities (i.e., 3167 and $2213 \mathrm{mAh} \mathrm{g}^{-1}$ for 80nSi/10BCNF16A and 60nSi/30BCNF16A electrodes, respectively, in the 2nd cycle).

Table 1. Specific discharge capacity $\left(C_{\text {disc }}\right)$ in the 1 st, 2 nd, 10th, 20th and 30th cycles, irreversible capacity in the 1 st cycle $\left(C_{\text {irr }}\right)$ and capacity retention $(R)$ parameters from the galvanostatic cycling vs. $\mathrm{Li} / \mathrm{Li}^{+}$of Si-based electrodes with different proportions of nSi and BCNFs, at an electric current density of $100 \mathrm{~mA} \mathrm{~g}^{-1}$.

\begin{tabular}{|c|c|c|c|c|c|c|c|}
\hline Electrode & $\begin{array}{c}C_{\text {disc }} \\
\text { 1st Cycle } \\
\left(\mathrm{mAh}^{-1}\right)\end{array}$ & $\begin{array}{c}C_{\text {disc }} \\
\text { 2nd Cycle } \\
\left(\mathrm{mAh}^{-1}\right)\end{array}$ & $\begin{array}{c}C_{\text {disc }} \\
\text { 10th Cycle } \\
\left(\mathrm{mAh}^{-1}\right)\end{array}$ & $\begin{array}{c}C_{\text {disc }} \\
\text { 20th Cycle } \\
\left(\mathrm{mAh}^{-1}\right)\end{array}$ & $\begin{array}{c}C_{\text {disc }} \\
\text { 30th Cycle } \\
\left(\mathrm{mAh}^{-1}\right)\end{array}$ & $\begin{array}{c}C_{\text {irr }}{ }^{a} \\
\text { 1st Cycle } \\
(\%)\end{array}$ & $\begin{array}{c}R^{\mathrm{b}} \\
\text { 2nd-30th } \\
\text { Cycles (\%) }\end{array}$ \\
\hline 80nSi/10BCNF27*G & 1871 & 1343 & 607 & - & - & - & - \\
\hline 60nSi/30BCNF27*G & 1803 & 1473 & 512 & - & - & - & - \\
\hline $45 \mathrm{nSi} / 45 \mathrm{BCNF} 27^{*} \mathrm{G}$ & 1900 & 1549 & 237 & 146 & 136 & 21 & 9 \\
\hline 30nSi/60BCNF27*G & 1187 & 867 & 218 & 108 & 62 & 30 & 7 \\
\hline $10 \mathrm{nSi} / 80 \mathrm{BCNF} 27^{*} \mathrm{G}$ & 718 & 468 & 287 & 155 & 187 & 39 & 40 \\
\hline 80nSi/10BCNF27*A & 2643 & 1890 & 464 & 346 & 229 & 30 & 12 \\
\hline 60nSi/30BCNF27*A & 2525 & 1957 & 753 & 464 & 314 & 37 & 16 \\
\hline $45 \mathrm{nSi} / 45 \mathrm{BCNF} 27^{*} \mathrm{~A}$ & 3191 & 2852 & 1558 & 904 & 534 & 28 & 19 \\
\hline 30nSi/60BCNF27*A & 1181 & 1043 & 748 & 407 & 183 & 14 & 15 \\
\hline $10 \mathrm{nSi} / 80 \mathrm{BCNF} 27^{*} \mathrm{~A}$ & 738 & 465 & 343 & 183 & 126 & 49 & 27 \\
\hline 80nSi/10BCNF16A & 3964 & 3167 & 1272 & 946 & 748 & 28 & 24 \\
\hline 60nSi/30BCNF16A & 2439 & 2213 & 874 & 569 & 391 & 18 & 18 \\
\hline $45 \mathrm{nSi} / 45 \mathrm{BCNF} 16 \mathrm{~A}$ & 1916 & 1640 & 834 & 696 & 545 & 15 & 33 \\
\hline 30nSi/60BCNF16A & 1516 & 1325 & 458 & 174 & 99 & 27 & 7 \\
\hline 10nSi/80BCNF16A & 800 & 574 & 405 & 242 & 235 & 38 & 41 \\
\hline $\mathrm{nSi}$ & 3554 & 1747 & 302 & 155 & 118 & - & 8 \\
\hline
\end{tabular}

${ }^{\mathrm{a}}$ Irreversible capacity $(\%)=\left[C_{\text {disc }}(1\right.$ st cycle $)-C_{\text {charge }}(1$ st cycle $\left.)\right]\left[C_{\text {disc }}(1 \text { st cycle })\right]^{-1} \times 100 .{ }^{b}$ Capacity retention $(\%)$

$=\left[C_{\text {disc }}(30\right.$ th cycle $\left.)\right]\left[C_{\text {disc }}(2 \text { nd cycle })\right]^{-1} \times 100$.

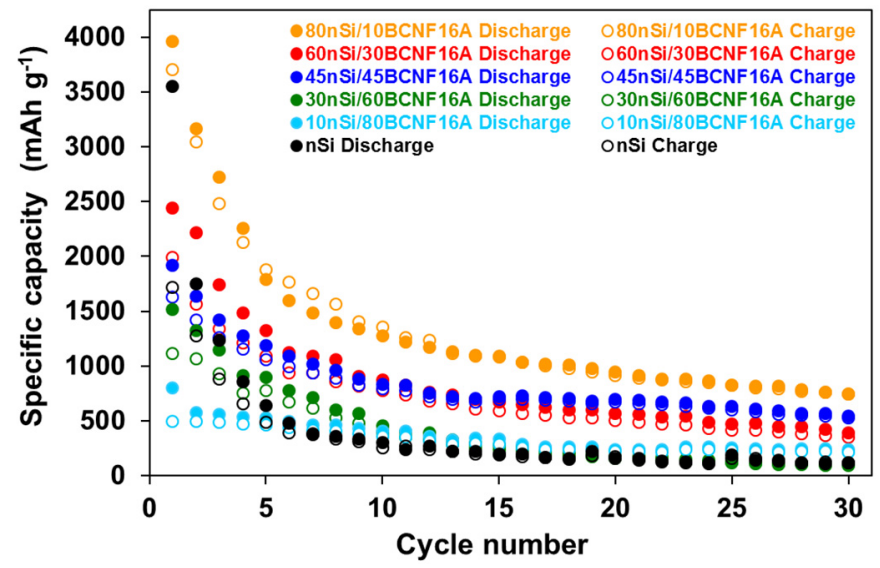

Figure 1. Specific discharge/charge capacity against cycle number plots from the galvanostatic cycling vs. $\mathrm{Li} / \mathrm{Li}^{+}$at $100 \mathrm{~mA} \mathrm{~g}^{-1}$ of $\mathrm{nSi}$, of 10nSi/80BCNF16A, 30nSi/60BCNF16A, 45nSi/45BCNF16A, 60nSi/30BCNF16A and 80nSi/10BCNF16A electrodes, in the $2.1 \mathrm{~V}-3 \mathrm{mV}$ potential range.

Nevertheless, the discharge capacity of these electrodes in which the carbon matrix is the minority part of the active composite ( $\leq 30 \mathrm{wt}$. $\%$ ) fades progressively in the following cycles, thus leading to very low retention capacity at the end of cycling. As an example, between cycles 2 and 20, the discharge capacity provided by the abovementioned electrodes decreased by around $70 \%$. This negative 
effect is more evident for $80 \mathrm{nSi} / 10 \mathrm{BCNF} 27^{*} \mathrm{~A}$ and $60 \mathrm{nSi} / 30 \mathrm{BCNF} 27^{*} \mathrm{~A}$ electrodes, which underwent capacity losses of $82 \%$ and $76 \%$, respectively, in the same cycling period. Furthermore, as seen in Table 1 , no capacity was detected for $80 \mathrm{nSi} / 10 \mathrm{BCNF} 27^{*} \mathrm{G}$ and $60 \mathrm{nSi} / 30 \mathrm{BCNF} 27^{*} \mathrm{G}$ electrodes after 10 discharge-charge cycles.

Therefore, it is evident that, under these conditions, the BCNFs carbon matrices, particularly $\mathrm{BCNF} 27^{*} \mathrm{G}$, are not accommodating the volume changes associated with the lithiation/delithiation process of the electrodes. An increase of the relative proportion of the carbon matrix in the active composite from 10 to $30 \mathrm{wt} . \%$, up to $45 \mathrm{wt} . \%$ (nSi:BCNFs weight percentages ratio of 45:45), in particular for BCNF16A, improves the electrode performance as a whole (Table 1 and Figure 1). In this context, although the 2 nd cycle discharge capacity of $45 \mathrm{nSi} / 45 \mathrm{BCNF} 16 \mathrm{~A}$ electrode is much lower than those of $80 \mathrm{nSi} / 10 \mathrm{BCNF} 16 \mathrm{~A}$ and $60 \mathrm{nSi} / 30 \mathrm{BCNF} 16 \mathrm{~A}$ because of the lesser relative amount of $\mathrm{nSi}$, its stability along cycling is better as shown by the higher capacity retention $(R)$ at the end of 30 discharge-charge cycles (33\% against $18-24 \%$ ). Moreover, $45 \mathrm{nSi} / 45 \mathrm{BCNF} 16 \mathrm{~A}$ shows a plateau between the 12 th and 25 th cycle, in which this electrode supplies a specific capacity up to $\sim 700 \mathrm{mAh} \mathrm{g}^{-1}$ with a great retention value of $85 \%$. Accordingly, a nSi:BCNF16A percentage weight ratio of 45:45 in the active composite seems to be the most optimal, since it allows a compromise between a suitable specific capacity, which is higher than that of graphitic materials currently commercialized for LIBs, and an acceptable capacity retention along cycling. To a lesser extent, this nSi:C ratio also leads to an enhancement of the electrode parameters by using $\mathrm{BCNF} 27^{*} \mathrm{~A}$ carbon matrix. As an example, at the end of cycling, a discharge capacity of $534 \mathrm{mAh} \mathrm{g}^{-1}$ was measured for $45 \mathrm{nSi} / 45 \mathrm{BCNF} 27^{*} \mathrm{~A}$ in contrast to a value of $126 \mathrm{mAh} \mathrm{g}^{-1}$ for $10 \mathrm{nSi} / 80 \mathrm{BCNF} 27^{*} \mathrm{~A}$ (Table 1). However, except during the 2nd cycle, no improvement is observed for those electrodes prepared with the graphitized $B C N F 27^{*} \mathrm{G}$ carbon matrix. By comparing these electrochemical results and the textural properties of the BCNFs carbon matrices in Table 2, it is obvious that the decrease of the porosity and the surface area, which are associated with the graphitization treatment $\left(\mathrm{BCNF} 27^{*} \mathrm{~A}\right.$ against $\left.\mathrm{BCNF} 27^{*} \mathrm{G}\right)$, has a negative impact on the capability of these nanomaterials to accommodate the volume changes during the lithiation/delithiation process. Nevertheless, other factors different than BCNFs textural properties should be responsible of their performance as carbon matrices, since BCNF16A having somewhat lower surface area and porosity than $B C N F 27^{*} A$ leads to better electrochemical results (Table 1). From TEM observations [32], it was concluded that the BCNFs produced at $600{ }^{\circ} \mathrm{C}(\mathrm{BCNF} 16 \mathrm{~A})$ have fishbone (parallel graphene layers tilted with respect to the fiber axis) microstructure, whereas mixtures of fishbone and ribbon (parallel graphene layers which are parallel with respect to the fiber axis) microstructures were detected in those obtained at $700{ }^{\circ} \mathrm{C}\left(\mathrm{BCNF} 27^{*} \mathrm{~A}\right)$. Considering that the number of active edge sites in a fishbone microstructure is much higher than in a ribbon type, BCNFs such as BCNF16A might better interact with nSi particles in the composite, somehow favoring their role as carbon matrix.

Table 2. Textural parameters of carbon matrices: BET surface area $\left(S_{\mathrm{BET}}\right)$, Total $\mathrm{N}_{2}$ pore volume $\left(V_{\mathrm{t}}\right)$, mesopore volume ( $V_{\text {MESO }}$ ) and micropore volume $\left(V_{\text {MICRO }}\right)$.

\begin{tabular}{ccccc}
\hline Carbon Matrix & $S_{\text {BET }}\left(\mathbf{m}^{\mathbf{2}} \mathbf{g}^{\mathbf{1}}\right)$ & $V_{\mathbf{t}}\left(\mathbf{c m}^{\mathbf{3}} \mathbf{g}^{\mathbf{- 1}}\right)$ & $V_{\text {MESO }}\left(\mathbf{c m}^{\mathbf{3}} \mathbf{g}^{\mathbf{1}}\right)$ & $V_{\text {MICRO }}\left(\mathbf{c m}^{\mathbf{3}} \mathbf{g}^{-\mathbf{1}}\right)$ \\
\hline BCNF16A & 96 & 0.240 & 0.171 & 0.011 \\
BCNF27*A & 113 & 0.392 & 0.333 & 0.010 \\
BCNF27*G & 73 & 0.279 & 0.279 & 0.010 \\
rGO & 460 & - & - & - \\
PR24G & 29 & - & - & - \\
\hline
\end{tabular}

For comparative purposes, the galvanostatic plots (specific capacity against cycle number) of 45nSi/45BCNF16A and 45nSi/45BCNF27* G electrodes are presented in Figure 2 together with those in which the commercial nanomaterials: graphitized nanofibers PR24G (45nSi/45PR24G electrode) and reduced graphene oxide $\mathrm{rGO}(45 \mathrm{nSi} / 45 \mathrm{rGO}$ electrode) are the carbon matrices in the active composites. Unlike BCNF27*G [32], the use of PR24G carbon matrix, which is likewise a graphitic 
nanomaterial [38], initially (1st to 10th cycle) leads to a specific capacity comparable to that determined for $45 \mathrm{nSi} / 45 \mathrm{BCNF} 16 \mathrm{~A}$ electrode. Nevertheless, in the subsequent cycles, a gradual decrease of the specific capacity provided by $45 \mathrm{nSi} / 45 \mathrm{PR} 24 \mathrm{G}$ to a final value of $200 \mathrm{mAh} \mathrm{g}^{-1}$, which is in the order of that measured for $45 \mathrm{nSi} / 45 \mathrm{BCNF} 27^{*} \mathrm{G}$ electrode, is observed. Therefore, it appears that PR24G material accommodates the volume changes associated with lithium insertion/deinsertion to a much greater extent than BCNF27*G. Keeping in mind that PR24G shows a lower surface area $\left(29 \mathrm{~m}^{2} \mathrm{~g}^{-1}\right.$ versus $73 \mathrm{~m}^{2} \mathrm{~g}^{-1}$ for BCNF27*G in Table 2$)$, the ability of these graphitic nanofilaments to better counteract the negative effect of the volume changes could be only attributed to their stacked-cup microstructure [38], in which the circular section formed by nested (stacked) cones surrounding an inner hollow core provides an extra space for accommodating these changes. Overall, the performance of the Si-based electrode that was prepared with the reduced graphene oxide as the carbon matrix $(45 \mathrm{nSi} / 45 \mathrm{rGO})$ is comparable to that of $45 \mathrm{nSi} / 45 \mathrm{BCNF} 16 \mathrm{~A}$.

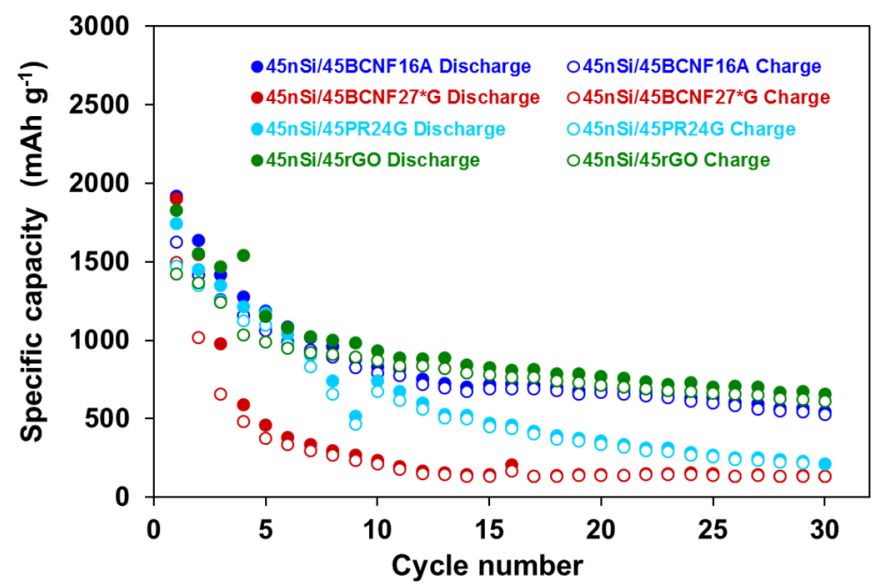

Figure 2. Specific discharge/charge capacity against cycle number plots from the galvanostatic cycling vs. $\mathrm{Li} / \mathrm{Li}^{+}$at $100 \mathrm{~mA} \mathrm{~g}^{-1}$ of $\mathrm{nSi} / \mathrm{C}$ electrodes with equal $\mathrm{nSi}: \mathrm{C}$ weight ratio and different carbon matrix, namely $45 \mathrm{nSi} / 45 \mathrm{BCNF} 16 \mathrm{~A}, 45 \mathrm{nSi} / 45 \mathrm{BCNF} 27^{*} \mathrm{G}, 45 \mathrm{nSi} / 45 \mathrm{PR} 24 \mathrm{G}$ and $45 \mathrm{nSi} / 45 \mathrm{rGO}$, in the $2.1 \mathrm{~V}-3 \mathrm{mV}$ potential range.

Based on these results, it can be concluded that either no-graphitized carbon nanofibers, particularly those with fishbone microstructure, or low surface area such as BCNF16A, and/or carbon materials supporting a laminar structure and large surface area, such as $\mathrm{rGO}\left(S_{\mathrm{BET}} \sim 460 \mathrm{~m}^{2} \mathrm{~g}^{-1}\right)$, are suitable carbon matrices for Si-based anodes, because they are able to accommodate the volume changes associated with lithium insertion/deinsertion, thus preventing electrode degradation.

\subsection{Influence of Cycling Conditions on the Electrochemical Performance of 45nSi/45BCNF16A Electrode}

As seen in the previous section, the use of $\mathrm{nSi} / \mathrm{BCNF}$ composites improves significantly the electrode performance compared to one of pure nSi, particularly in the case of $45 \mathrm{nSi} / 45 \mathrm{BCNF} 16 \mathrm{~A}$. Even so, the capacity retention along cycling, specifically during the first ten discharge-charge cycles, is still far from excellent and, therefore, it should be increased. On this matter, the influence of cycling conditions, specifically the potential window on the 45nSi/45BCNF16A electrode performance, is herein investigated. First of all, in order to gain further insight into the interaction of the $\mathrm{Li}^{+}$ions with the active composite during the galvanostatic process, the differential charge/discharge capacity against potential vs. $\mathrm{Li} / \mathrm{Li}^{+}(<1 \mathrm{~V})$ plot for the 1 st, 2 nd and 3 rd cycles of the $45 \mathrm{nSi} / 45 \mathrm{BCNF} 16 \mathrm{~A}$ electrode in Figure 3 is discussed. During the first discharge, the potential drops rapidly until $\sim 0.1 \mathrm{~V}$. At this voltage, a broad band associated with the initial lithiation of the crystalline silicon (c-Si) to form an amorphous undefined $\mathrm{a}-\mathrm{Li}_{\mathrm{x}} \mathrm{Si}$ alloy is observed. In the subsequent charge, a well-defined peak at $\sim 0.44 \mathrm{~V}$, which has been ascribed to the delithiation of the a- $\mathrm{Li}_{15} \mathrm{Si}_{4}$ alloy to produce amorphous silicon (a-Si), appears. The lithiation of a-Si during the second discharge results in two bands $(\sim 0.24 \mathrm{~V}$ and 
$\sim 0.08 \mathrm{~V}$ ) and a smaller one at $<0.04 \mathrm{~V}$, which corresponds to the formation of the abovementioned a- $\mathrm{Li}_{15} \mathrm{Si}_{4}$ phase. As expected, in the following charge cycle, the peak at $0.44 \mathrm{~V}$ from the delithiation of this phase is also detected. This is in line with the observations of Obrovac et al. [37] and Li et al. [39] for the lithiation/delithiation mechanism of silicon electrodes. Furthermore, these authors have reported that the $\mathrm{Li}_{15} \mathrm{Si}_{4}$ phase is formed when the lower cutoff voltage is $<50 \mathrm{mV}$ ( $3 \mathrm{mV}$ in this work).

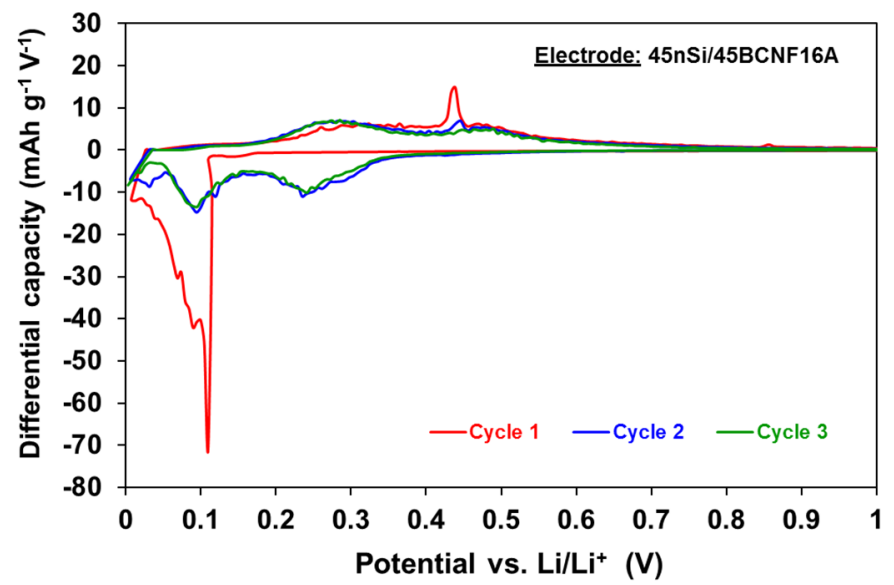

Figure 3. Differential charge/discharge capacity against potential vs. $\mathrm{Li} / \mathrm{Li}^{+}$plots from the galvanostatic cycling at $100 \mathrm{~mA} \mathrm{~g}^{-1}$ of $45 \mathrm{nSi} / 45 \mathrm{BCNF} 16 \mathrm{~A}$ electrode for cycles $1 \mathrm{st}$, 2nd and 3rd, in the $2.1 \mathrm{~V}-3 \mathrm{mV}$ potential range.

According to Obrovac et al. [37], the formation of a stable microstructure composed of a central crystalline $\mathrm{Si}$ that remains intact and a crust of amorphous $\mathrm{Si}$ in charge of the accommodation of $\mathrm{Li}^{+}$ ions could allow for greater control of the volume changes, thus preventing electrode damage. To this aim, it is necessary (i) to limit the access of $\mathrm{Li}^{+}$ions during the first cycle, so that the c-Si lithiation is not complete, but it is sufficient to obtain a significant capacity value; and (ii) to avoid the formation of $\mathrm{Li}_{15} \mathrm{Si}_{4}$ phase during the subsequent cycles, which would imply the complete electrode lithiation. However, the coincidence of both phenomena in the same potential range makes the simultaneous fulfillment of both requirements difficult. Therefore, it is necessary to reach a compromise through the determination of the most suitable potential range. To this end, 45nSi/45BCNF16A electrode was subjected to galvanostatic cycling at a constant current density of $100 \mathrm{~mA} \mathrm{~g}^{-1}$ for 50 cycles between an upper cutoff voltage (UCOV) of $0.9 \mathrm{~V}$ and a lower cutoff voltage (LCOV) ranging from 3 to $120 \mathrm{mV}$. The galvanostatic plots (specific capacity against cycle number) and the corresponding differential charge-discharge capacity against potential vs. $\mathrm{Li} / \mathrm{Li}^{+}$plots for the 1 st, 2 nd and 3rd cycles are presented in Figures 4 and 5, respectively.

Based on the differential capacity profiles of the first cycle (Figure 5), at a LCOV of $120 \mathrm{mV}$, the lithiation of the electrode has basically not yet started, and this limits its performance along the cycling (Figure 4). As expected, a decrease of the LCOV, from 120 to $3 \mathrm{mV}$, leads to an improvement in the capacity values during the first cycles, but the capacity retention decreases at the same time, due to the progressive electrode damage. This fact is in accordance with the aforementioned study of Obrovac et al. for Si anodes [37]. Thus, a specific capacity up to $520 \mathrm{mAh} \mathrm{g}^{-1}$ at 30th cycle with cycling efficiency $>95 \%$ and excellent capacity retention $(\mathrm{R} \sim 94 \%)$ is determined for $45 \mathrm{nSi} / 45 \mathrm{BCNF} 16 \mathrm{~A}$ electrode at a LCOV of $100 \mathrm{mV}$. Although these values decrease after 50 discharge-charge cycles, they

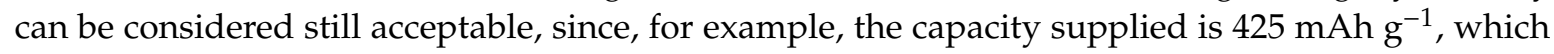
supposes an increase of $\sim 90 \%$ with respect to the capacity of a graphite anode at the same current density ( 224 $\mathrm{mAh} \mathrm{g}^{-1}$ at $100 \mathrm{~mA} \mathrm{~g}^{-1}$ ) [40]. A subsequent LCOV reduction to $80 \mathrm{mV}$ causes an increase of the specific capacity along the first cycles, but basically does not affect it after the 15th cycle. From this point, both curves are almost overlapping with a value of $\mathrm{R} \sim 74 \%$ in the 20th-50th cycles (Figure 4). However, for LCOV in the $60-20 \mathrm{mV}$ range, a continuous specific capacity loss along cycling occurs 
( $<200 \mathrm{mAh} \mathrm{g}^{-1}$ after 50 cycles). The formation of the lithiated $\mathrm{Li}_{15} \mathrm{Si}_{4}$ phase, which is proved by the presence of the $0.04 \mathrm{~V}$ peak in the differential capacity against potential plots (Figure 5), accounts for this negative effect, since it involves the Si crystallization and, therefore, a microstructural change that contributes to electrode damage. This phenomenon is particularly appreciated in the differential capacity plots at LCOV of 40, 20 and $3 \mathrm{mV}$. Furthermore, for LCOV $\leq 20 \mathrm{mV}$, the peak corresponding to the delithiation of $\mathrm{Li}_{15} \mathrm{Si}_{4}$ phase $(0.44 \mathrm{~V})$ is also observed. However, this peak is not detectable at $\geq 40 \mathrm{mV}$, probably because the amount of this phase is still very small.

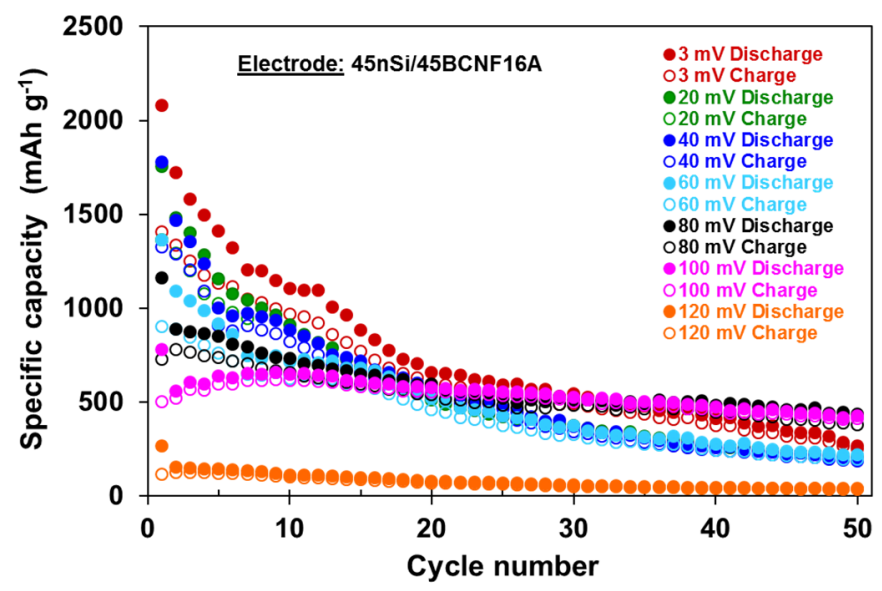

Figure 4. Specific discharge/charge capacity against cycle number plots from the galvanostatic cycling vs. $\mathrm{Li} / \mathrm{Li}^{+}$at $100 \mathrm{~mA} \mathrm{~g}^{-1}$ of $45 \mathrm{nSi} / 45 \mathrm{BCNF} 16 \mathrm{~A}$ electrode, in the $0.9 \mathrm{~V}$ to $X \mathrm{mV}$ potential range. $X=$ lower cutoff voltage (LCOV).

In summary, at LCOV in the $80-100 \mathrm{mV}$ range, it is possible to control the continuous microstructural changes of the silicon, thus restricting the volume changes experienced by the electrode during the lithiation/delithiation process, which leads to values of capacity retention and efficiency comparable to commercial materials, such as graphite, and a specific capacity 2.5 times larger than these materials under similar conditions [40].

In order to corroborate these observations, the galvanostatic cycling of the $45 \mathrm{nSi} / 45 \mathrm{BCNF} 16 \mathrm{~A}$ electrode was also performed, applying a LCOV of $80 \mathrm{mV}$, at a higher electric current density of 200 $\mathrm{mA} \mathrm{g}^{-1}$. The specific capacity against cycle number plots of this electrode, at both 200 and $100 \mathrm{~mA}$ $\mathrm{g}^{-1}$, are shown in Figure 6. As seen, the corresponding profiles are almost overlapping, i.e., both capacity provided and capacity retention are hardly invariable after 30 cycles when the applied current is double, which means a five times greater specific capacity than that supplied by a graphite electrode in similar conditions [40]. 

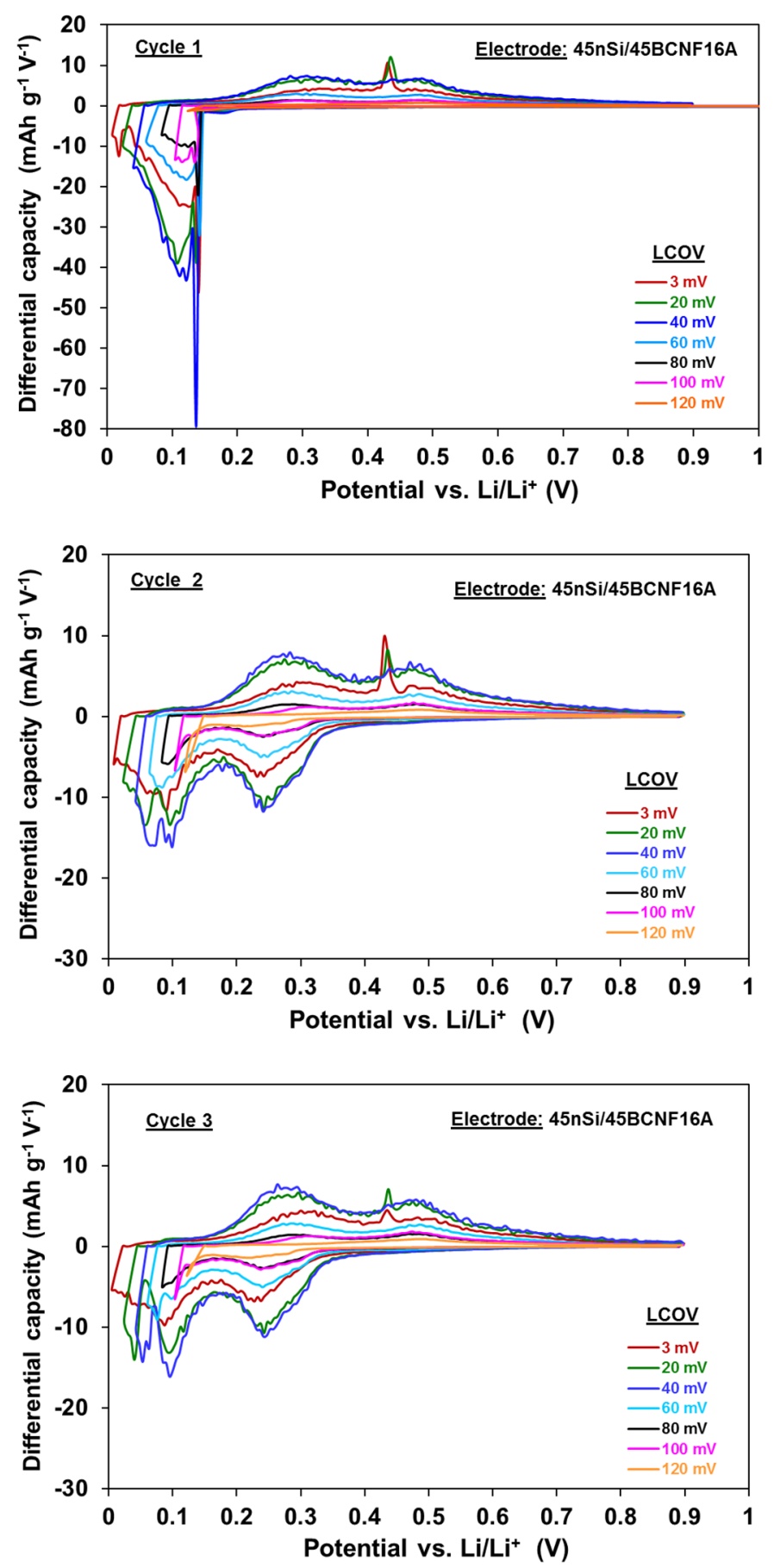

Figure 5. Differential charge/discharge capacity against potential vs. $\mathrm{Li} / \mathrm{Li}^{+}$plots from the galvanostatic cycling at $100 \mathrm{~mA} \mathrm{~g}^{-1}$ of $45 \mathrm{nSi} / 45 \mathrm{BCNF} 16 \mathrm{~A}$ electrode for cycles $1 \mathrm{st}, 2 \mathrm{nd}$ and $3 \mathrm{rd}$, in the $0.9 \mathrm{~V}-\mathrm{X} \mathrm{mV}$ potential range. $X=$ lower cutoff voltage (LCOV). 


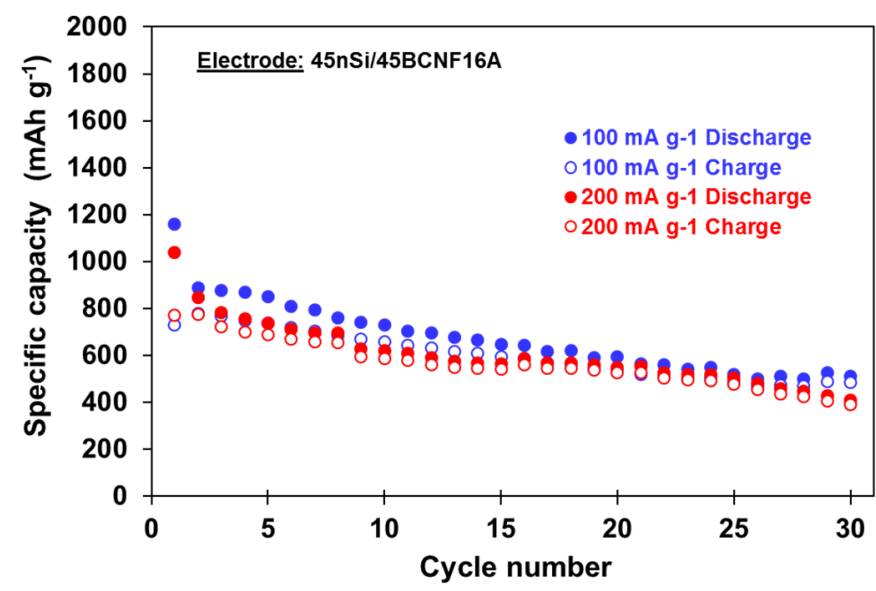

Figure 6. Specific discharge/charge capacity against cycle number plots from the galvanostatic cycling vs. $\mathrm{Li}_{/} \mathrm{Li}^{+}$at 100 and $200 \mathrm{~mA} \mathrm{~g}{ }^{-1}$ of $45 \mathrm{nSi} / 45 \mathrm{BCNF} 16 \mathrm{~A}$ electrode, in the $0.9 \mathrm{~V}-80 \mathrm{mV}$ potential range.

\section{Conclusions}

Nano-silicon/biogas-derived carbon nanofibers composites (nSi/BCNFs) that were prepared by a simple, fast and easily industrial-scaling process were successfully applied as anode materials in lithium-ion batteries, substantially improving the nano-silicon electrode performance, in regard to both capacity and stability. Specific capacities up to $520 \mathrm{mAh} \mathrm{g}^{-1}$ with coulombic efficiency $>95 \%$ and $94 \%$ of capacity retention along cycling were achieved for $\mathrm{nSi} / \mathrm{BCNF}$ anodes at an electric current density of 100/200 $\mathrm{mA} \mathrm{g}^{-1}$ and a low cutoff voltage of $80 \mathrm{mV}$.

Among the BCNFs studied, the no-graphitized ones, which were directly obtained from the catalytic decomposition of biogas, with fishbone microstructure, therefore having a great number of active sites to interact with the nSi particles in the composite, were found to be the most suitable carbon matrices, because they are able to better buffer the volume changes associated with the silicon lithiation/delithiation process, thus preventing electrode degradation. Specifically, an nSi:BCNFs 1:1 weight ratio in the anode active composite is the most optimal, since it allows a compromise between a suitable specific capacity, which is greater than that of graphitic materials currently used in LIBs, and an acceptable capacity retention along cycling.

The limitation of the potential cycling range of $\mathrm{nSi} / \mathrm{BCNFs}$ anodes may control the continuous microstructural changes of the silicon, thus restricting the volume changes experienced by these anodes, which finally enhances their output, particularly the stability. Low cutoff voltage in the $80-100 \mathrm{mV}$ range was found to be the best for the galvanostatic cycling of $\mathrm{nSi} / \mathrm{BCNFs}$ anodes, because it avoids the formation of the highest lithiated phase $\left(\mathrm{L}_{15} \mathrm{Si}_{4}\right)$ and, therefore, the complete silicon lithiation, which leads to electrode damage.

Supplementary Materials: The following are available online at http://www.mdpi.com/2311-5629/6/2/25/s1. Figure S1: Specific discharge capacity in the 1st, 10th, 20th and 30th cycles from the galvanostatic cycling of different micro-silicon $(x \mathrm{mSi} / \mathrm{yB})$-based and nano-silicon $(x \mathrm{nSi} / y \mathrm{~B})$-based electrodes, at an electric current density of $37.2 \mathrm{~mA} \mathrm{~g}^{-1}$, in the $2.1 \mathrm{~V}-3 \mathrm{mV}$ potential range. $\mathrm{B}$ is the binder, namely sodium carboxymethyl cellulose $(\mathrm{NaCMC})$ and Xanthan gum $(\mathrm{XG})$, and $x$ and $y$ are the weight percentages of silicon and binder, respectively, in the electrode. Figure S2: Specific discharge capacity against cycle number plots from the galvanostatic cycling of $70 \mathrm{nSi} / 10 \mathrm{E} / 20 \mathrm{NaCMC}$ electrodes (E: CB, SG-KS6 or BCNF27 ${ }^{*} \mathrm{G}$ ) and $80 \mathrm{nSi} / 20 \mathrm{NaCMC}$ electrode at an electric current density of $37.2 \mathrm{~mA} \mathrm{~g}^{-1}$, in the $2.1 \mathrm{~V}-3 \mathrm{mV}$ potential range. Figure S3: Specific capacity against cycle number plots from the galvanostatic cycling of DP, MM and SA electrodes, at an electric current density of $100 \mathrm{~mA} \mathrm{~g}^{-1}$, in the 2.1 V-3 mV potential range. Figure S4: SEM images of DP electrode (a) 250x and (c) 60,000x; and of SA electrode (b) 250x, (d) and (e) 60,000x. Figure S5: SEM/EDX images of (a) DP electrode and (b) SA electrode at 250x. Table S1: Loads (active material + binder) of the different working electrodes used in the galvanostatic cycling vs. $\mathrm{Li} / \mathrm{Li}^{+}$ experiments in the potential ranges of $2.1 \mathrm{~V}-3 \mathrm{mV}$ (data in Table 1 and Figures $1-3)$ and $0.9 \mathrm{~V}-\mathrm{X} \mathrm{mV}(X=$ lower cutoff voltage, LCOV, data in Figures 4-6), at $100 \mathrm{~mA} \mathrm{~g}^{-1}$. Table S2: Electric conductivity $(\sigma)$ and BET surface area $\left(S_{\mathrm{BET}}\right)$ of the conductive additives $(\mathrm{E})$. 
Author Contributions: Conceptualization, I.C., N.C., A.B.G. and A.R.; methodology, N.C.; investigation, I.C., N.C., A.B.G. and A.R.; writing-original draft preparation, N.C.; writing-review and editing, N.C., I.C. and A.B.G.; supervision, A.B.G.; project administration, A.B.G. and I.C.; funding acquisition, A.B.G. and I.C. All authors have read and agreed to the published version of the manuscript.

Funding: This research was funded by Spanish Ministries of Economy and Competitiveness MINECO (Project ENE2014-52189-C2-2-R) and Science, Innovation and Universities (Project RTI2018-094286-A-100), and Asturian Regional Government (GRUPIN 2018, Ref. IDI/2018/000234).

Acknowledgments: Financial support from the Spanish Ministries of Economy and Competitiveness MINECO and Science, Innovation and Universities and Asturias Regional Government is gratefully acknowledged. I. Cameán and N. Cuesta respectively acknowledge the funding from Fundación General CSIC (Programa ComFuturo) and from MINECO for Ph.D. grant (BES-2012-052711).

Conflicts of Interest: The authors declare no conflict of interest.

\section{References}

1. Nitta, N.; Wu, F.; Lee, J.T.; Yushin, G. Li-ion battery materials: Present and future. Mater. Today 2015, 18, 252-264. [CrossRef]

2. Mishra, A.; Mehta, A.; Basu, S.; Malode, S.J.; Shetti, N.P.; Shukla, S.S.; Nadagouda, M.N.; Aminabhavi, T.M. Electrode materials for lithium-ion batteries. Mater. Sci. Energy Technol. 2018, 1, 182-187. [CrossRef]

3. Ozanam, F.; Rosso, M. Silicon as anode material for Li-ion batteries. Mater. Sci. Eng. B 2016, $213,2-11$. [CrossRef]

4. Li, P.; Zhao, G.; Zheng, X.; Xu, X.; Yao, C.; Sun, W.; Dou, S.X. Recent progress on silicon-based anode materials for practical lithium-ion battery applications. Energy Storage Mater. 2018, 15, 422-446. [CrossRef]

5. Casimir, A.; Zhang, H.; Ogoke, O.; Amine, J.C.; Lu, J.; Wu, G. Silicon-based anodes for lithium-ion batteries: Effectiveness of materials synthesis and electrode preparation. Nano Energy 2016, 27, 359-376. [CrossRef]

6. Obrovac, M.N. Si-alloy negative electrodes for Li-ion batteries. Curr. Opin. Electrochem. 2018, 9, 8-17. [CrossRef]

7. Obrovac, M.N.; Christensen, L. Structural changes in silicon anodes during lithium insertion/extraction. Electrochem. Solid State Lett. 2004, 7, A93-A96. [CrossRef]

8. Ryu, J.H.; Kim, J.W.; Sung, Y.-E.; Oh, S.M. Failure modes of silicon powder negative electrode in lithium secondary batteries. Electrochem. Solid State Lett. 2004, 7, A306-A309. [CrossRef]

9. Song, M.-K.; Park, S.; Alamgir, F.M.; Cho, J.; Liu, M. Nanostructured electrodes for lithium-ion and lithium-air batteries: The latest developments, challenges, and perspectives. Mater. Sci. Eng. R Rep. 2011, 72, $203-252$. [CrossRef]

10. Xu, W.; Vegunta, S.S.S.; Flake, J.C. Surface-modified silicon nanowire anodes for lithium-ion batteries. J. Power Sources 2011, 196, 8583-8589. [CrossRef]

11. Shen, X.; Tian, Z.; Fan, R.; Shao, L.; Zhang, D.; Cao, G.; Kou, L.; Bai, Y. Research progress on silicon/carbon composite anode materials for lithium-ion battery. J. Energy Chem. 2018, 27, 1067-1090. [CrossRef]

12. Kasavajjula, U.; Wang, C.; Appleby, A.J. Nano- and bulk-silicon-based insertion anodes for lithium-ion secondary cells. J. Power Sources 2007, 163, 1003-1039. [CrossRef]

13. Liang, B.; Liu, Y.; Xu, Y. Silicon-based materials as high capacity anodes for next generation lithium ion batteries. J. Power Sources 2014, 267, 469-490. [CrossRef]

14. Shao, D.; Tang, D.; Yang, J.; Li, Y.; Zhang, L. Nano-structured composite of Si/(S-doped-carbon nanowire network) as anode material for lithium-ion batteries. J. Power Sources 2015, 297, 344-350. [CrossRef]

15. Morita, T.; Takami, N. Nano Si cluster-SiO $x$-C composite material as high-capacity anode material for rechargeable lithium batteries. J. Electrochem. Soc. 2006, 153, A425-A430. [CrossRef]

16. Szczech, J.R.; Jin, S. Nanostructured silicon for high capacity lithium battery anodes. Energy Environ. Sci. 2011, 4, 56-72. [CrossRef]

17. Magasinski, A.; Zdyrko, B.; Kovalenko, I.; Hertzberg, B.; Burtovyy, R.; Huebner, C.F.; Fuller, T.F.; Luzinov, I.; Yushin, G. Toward efficient binders for Li-ion battery Si-based anodes: Polyacrylic acid. ACS Appl. Mater. Interfaces 2010, 2, 3004-3010. [CrossRef]

18. Komaba, S.; Yabuuchi, N.; Ozeki, T.; Han, Z.-J.; Shimomura, K.; Yui, H.; Katayama, Y.; Miura, T. Comparative study of sodium polyacrylate and poly(vinylidene fluoride) as binders for high capacity Si-graphite composite negative electrodes in Li-ion batteries. J. Phys. Chem. C 2012, 116, 1380-1389. [CrossRef] 
19. Liu, W.-R.; Yang, M.-H.; Wu, H.-C.; Chiao, S.M.; Wu, N.-L. Enhanced cycle life of Si anode for Li-ion batteries by using modified elastomeric binder. Electrochem. Solid State Lett. 2005, 8, A100-A103. [CrossRef]

20. Buqa, H.; Holzapfel, M.; Krumeich, F.; Veit, C.; Novák, P. Study of styrene butadiene rubber and sodium methyl cellulose as binder for negative electrodes in lithium-ion batteries. J. Power Sources 2006, 161, 617-622. [CrossRef]

21. Mazouzi, D.; Lestriez, B.; Roué, L.; Guyomard, D. Silicon composite electrode with high capacity and long cycle life. Electrochem. Solid State Lett. 2009, 12, A215-A218. [CrossRef]

22. Li, J.; Lewis, R.; Dahn, J. Sodium carboxymethyl cellulose a potential binder for Si negative electrodes for Li-ion batteries. Electrochem. Solid State Lett. 2007, 10, A17-A20. [CrossRef]

23. Beattie, S.D.; Larcher, D.; Morcrette, M.; Simon, B.; Tarascon, J.-M. Si Electrodes for Li-Ion Batteries-A New Way to Look at an Old Problem. J. Electrochem. Soc. 2008, 155, A158-A163. [CrossRef]

24. Hochgatterer, N.; Schweiger, M.; Koller, S.; Raimann, P.; Wöhrle, T.; Wurm, C.; Winter, M. Silicon/graphite composite electrodes for high-capacity anodes: Influence of binder chemistry on cycling stability. Electrochem. Solid State Lett. 2008, 11, A76-A80. [CrossRef]

25. Bridel, J.S.; Azaïs, T.; Morcrette, M.; Tarascon, J.M.; Larcher, D. Key parameters governing the reversibility of $\mathrm{Si} /$ carbon/CMC electrodes for Li-ion batteries. Chem. Mater. 2010, 22, 1229-1241. [CrossRef]

26. Guo, J.; Wang, C. A polymer scaffold binder structure for high capacity silicon anode of lithium-ion battery. Chem. Commun. 2010, 46, 1428-1430. [CrossRef]

27. Lux, S.F.; Schmuck, M.; Jeong, S.; Passerini, S.; Winter, M.A.; Balducci, A. Li-ion anodes in air-stable and hydrophobic ionic liquid-based electrolyte for safer and greener batteries. Int. J. Energy Res. 2010, 34, 97-106. [CrossRef]

28. Kovalenko, I.; Zdyrko, B.; Magasinski, A.; Hertzberg, B.; Milicev, Z.; Burtovyy, R.; Luzinov, I.; Yushin, G. A major constituent of brown algae for use in high-capacity Li-ion batteries. Science 2011, 334, 75-79. [CrossRef]

29. Yue, L.; Zhang, L.; Zhong, H. Carboxymethyl chitosan: A new water soluble binder for Si anode of Li-ion batteries. J. Power Sources 2014, 247, 327-331. [CrossRef]

30. Kuruba, R.; Datta, M.K.; Damodaran, K.; Jampani, P.H.; Gattu, B.; Patel, P.P.; Shanthi, P.M.; Damle, S.; Kumta, P.N. Guar gum: Structural and electrochemical characterization of natural polymer based binder for silicon-carbon composite rechargeable Li-ion battery anodes. J. Power Sources 2015, 298, 331-340. [CrossRef]

31. Ling, M.; Xu, Y.; Zhao, H.; Gu, X.; Qiu, J.; Li, S.; Wu, M.; Song, X.; Yan, C.; Liu, G.; et al. Dual-functional gum arabic binder for silicon anodes in lithium ion batteries. Nano Energy 2015, 12, 178-185. [CrossRef]

32. Cuesta, N.; Cameán, I.; Ramos, A.; de Llobet, S.; García, A.B. Graphitic nanomaterials from biogas-derived carbon nanofibers. Fuel Process. Technol. 2016, 152, 1-6. [CrossRef]

33. Leveau, L.; Laïk, B.; Pereira-Ramos, J.-P.; Gohier, A.; Tran-Van, P.; Cojocaru, C.-S. Cycling strategies for optimizing silicon nanowires performance as negative electrode for lithium battery. Electrochim. Acta 2015, 157, 218-224. [CrossRef]

34. Cui, L.-F.; Ruffo, R.; Chan, C.K.; Peng, H.; Cui, Y. Crystalline-amorphous core-shell silicon nanowires for high capacity and high current battery electrodes. Nano Lett. 2009, 9, 491-495. [CrossRef] [PubMed]

35. Chan, C.K.; Peng, H.; Liu, G.; McIlwrath, K.; Zhang, X.F.; Huggins, R.A.; Cui, Y. High-performance lithium battery anodes using silicon nanowires. Nature Nanotechol. 2008, 3, 31-35. [CrossRef] [PubMed]

36. Liu, X.H.; Wang, J.W.; Huang, S.; Fan, F.; Huang, X.; Liu, Y.; Krylyuk, S.; Yoo, J.; Dayeh, S.A.; Davydov, A.V. In situ atomic-scale imaging of electrochemical lithiation in silicon. Nature Nanotechol. 2012, 7, 749-756. [CrossRef]

37. Obrovac, M.N.; Krause, L.J. Reversible cycling of crystalline silicon powder. J. Electrochem. Soc. 2007, 154, A103-A108. [CrossRef]

38. Ramos, A.; Cameán, I.; Cuesta, N.; García, A.B. Graphitized stacked-cup carbon nanofibers as anode materials for lithium-ion batteries. Electrochim. Acta 2014, 146, 769-775. [CrossRef]

39. Li, J.; Dahn, J.R. An in situ X-Ray diffraction study of the reaction of Li with crystalline Si. J. Electrochem. Soc. 2007, 154, A156-A161. [CrossRef]

40. Cuesta, N.; Cameán, I.; Ramos, A.; García, A.B. Graphitized biogas-derived carbon nanofibers as anodes for lithium-ion batteries. Electrochim. Acta 2016, 222, 264-270. [CrossRef] 
(C) 2020 by the authors. Licensee MDPI, Basel, Switzerland. This article is an open access article distributed under the terms and conditions of the Creative Commons Attribution (CC BY) license (http://creativecommons.org/licenses/by/4.0/). 